\title{
Libras na educação de surdos: o que dizem os profissionais da escola?
}

\author{
Carine Mendes da Silva \\ Universidade de Brasília - Brasília - DF - Brasil \\ Daniele Nunes Henrique Silva \\ Universidade de Brasília - Brasília - DF - Brasil
}

\begin{abstract}
Resumo
A inclusão educacional de surdos tem sido frequentemente debatida, especialmente pela condição bilíngue e bicultural dos alunos, que exige práticas diferenciadas de ensino que partem da Língua Brasileira de Sinais. O objetivo do estudo foi entender o que os profissionais da escola dizem sobre o papel desta língua. Participaram da pesquisa a diretora, o supervisor pedagógico, a coordenadora de linguagens e códigos, a coordenadora de humanas, o coordenador de exatas, o professor de português como segunda língua, a professora da sala de recursos e a intérprete de Libras. O trabalho de campo foi realizado em uma escola de ensino médio da rede pública, do Distrito Federal, através de entrevistas semiestruturadas. Das análises depreendeu-se um eixo relacionado à centralidade (ou não) da Libras para o desenvolvimento bicultural dos surdos. Os participantes da pesquisa formularam críticas aos processos de escolarização dos surdos e à Língua de Sinais.
\end{abstract}

Palavras-chave: Inclusão; língua de sinais brasileira; educação especial.

\section{Libras in deaf students education: what do the professionals have to say about?}

\begin{abstract}
The educational inclusion of deaf students has often been debated, especially for bilingual and bicultural condition of the students, which requires differentiated teaching practices that depart from Brazilian Sign Language. The aim of the study was to understand what the school professionals say about the role of language. The participants were the director, the educational supervisor, the coordinator of languages and codes, the human coordinator, the exact sciences coordinator, Portuguese teacher as a second language, the resource room teacher and Libras interpreter. Fieldwork was conducted at a high school in the public system, in the Federal District in Brazil, through semi-structured interviews. Analyzes surmised to an axis related to the centrality (or not) Libras to the bicultural development of the deaf. Survey participants formulated critical exposure of schooling processes of the deaf and the Sign Language.
\end{abstract}

Keywords: Educational inclusion; brazilian sign language; special education.

\section{Libras en la educación de sordos: ¿lo qué dicen los profesionales de la escuela?}

\section{Resumen}

La inclusión educacional de sordos ha sido frecuentemente debatida, especialmente por la condición bilingüe y bicultural de los alumnos, que exige prácticas diferenciadas de enseñanza que parten de la Lengua Brasileña de Señas. El objetivo del estudio fue entender lo que los profesionales de la escuela dicen sobre el papel de esta lengua. Participaron de la investigación la directora, el supervisor pedagógico, la coordinadora de lenguajes y códigos, la coordinadora de humanas, el coordinador de exactas, el profesor de portugués como segunda lengua, la profesora del aula de recursos y la de intérprete de Libras. El trabajo de campo fue realizado en una escuela de enseñanza secundaria de la red pública, del Distrito Federal, por intermedio de entrevistas semiestructuradas. De los análisis se deprendió un eje relacionado a la centralidad (o no) de la Libras para el desarrollo bicultural de los sordos. Los participantes de la investigación formularon críticas a los procesos de escolarización de los sordos y a la Lengua de Señas.

Palabras clave: inclusión; lenguaje gestual o mimico brasilero; educadores de sordos. 


\section{Introdução}

Dados do último censo escolar (Inep/Mec, 2013) registram uma evolução nas matrículas dos alunos com necessidades educacionais na escola regular. De 382215, em 2000, para 636451, em 2012, o crescimento é de $66,51 \%$ de alunos incluídos na rede pública de ensino. Esse aumento quantitativo, contudo, ainda não se reverteu em amplo sucesso escolar. Os casos de estagnação acadêmica (repetência), fracasso e evasão são comuns quando o público é formado por alunos especiais (Michels, 2006).

Pesquisas, por exemplo, têm apontado (Kassar, 2011; Lacerda, 2007; Quadros, 2003) que estudantes que possuem necessidades especiais vivenciam uma inclusão pouco cuidadosa; reflexo da ausência de discussões pedagógicas sobre os pormenores gerados pela inserção dos alunos em classes regulares. Aspectos referentes às singularidades culturais, linguísticas, étnicas e/ou condições individuais, socioeconômicas etc. não são especificadas nos projetos pedagógicos. Há uma preocupação com a eficiência (custos) e eficácia (acesso e permanência dos alunos) na escola, o que por sua vez não garante a aprendizagem fundamental para o sucesso escolar (Garcia, 2013).

Em face dessas colocações, alguns desafios são impostos à implantação de propostas inclusivas: o papel da escola, as concepções dos profissionais sobre o significado da inclusão escolar, as relações entre ensino e aprendizagem, estratégias pedagógicas para a promoção de aprendizagens diferenciadas etc. Os apontamentos investigativos indicam, em seu turno, que o êxito da inclusão educacional depende da adesão do público e da reestruturação das escolas para atender a esse público, implicando em transformações de cunho pedagógico que são prioritárias frente ao desafio de incluir (Silva, 2014).

Para Mendes (2006) e Souza \& Lippe (2012) a política para escola inclusiva é controversa. Segundo esses autores, a inclusão se concretiza com base na idealização de uma escola para todos, que prioriza a convivência com a diferença, porém imersa nas contradições do próprio sistema neoliberal, despreza as particularidades dos estudantes em prol da homogeneização em torno do padrão.

No caso dos surdos, por exemplo, a situação é bastante agravada por se tratar de um público com características linguísticas e culturais específicas. Esses sujeitos possuem dificuldades para acessar a língua oral e por isso, desenvolvem-se a partir de processos simbólicos ancorados na Língua de Sinais (Quadros, 2012). Nessa perspectiva, a experiência de estudantes surdos dentro da escola merece atenção, uma vez que tais alunos apresentam aspectos que destoam do padrão social vigente, como será abordado adiante. Essas características envolvem questões sobre o desenvolvimento social, psicológico e cultural diferenciado que esses indivíduos possuem decorrente de sua condição bicultural ${ }^{1}$.

1 De fato, o surdo se constitui no entrever de duas culturas representativas de comunidades linguísticas distintas: uma hegemônica e outra contra hegemônica; uma oral e outra espacial; uma ouvinte e outra surda (Monteiro, 2014).

\section{Os desafios pedagógicos da educação de surdos: a língua de sinais}

A pessoa que não ouve possui um desenvolvimento marcado por características singulares, decorrentes de sua condição linguística e cultural. Pela condição biológica que o impede de acessar facilmente os discursos orais, o surdo depende de um canal diferente dos ouvintes para se expressar. Tal canal se realiza nas mãos, prioritariamente, e se pauta nas experiências visuais e gestuais (Kelman, Silva, Amorim, Monteiro, \& Azevedo, 2011). É por meio das mãos e de uma complexa expressão corporal captada pelos olhos, principalmente, que os surdos se comunicam e se constituem linguisticamente; sua língua, a Língua de Sinais, é sinalizada e se configura de modo diferente das línguas orais.

A Língua de Sinais é pautada na dimensão espacial, com estruturas semântica, sintática e gramatical completas, apesar de essencialmente distintas das línguas escritas e faladas (Sacks, 2010). As características dessa língua, especialmente no tocante à ausência de sonoridade, constituem de forma singular os processos de significação dos indivíduos que a utilizam. Para Dizeu e Caporalli (2005), o diferencial dessa língua na vida dos surdos minimiza as dificuldades de aprendizagem que é comum nas situações em que a eles é imposta a língua oral, pois aquela é adquirida sem necessidade de treinamentos árduos e repetitivos.

Nesse sentido, a Língua de Sinais é a língua dos surdos, sendo fundamental para o seu desenvolvimento em todas as esferas (sociolinguística, educacional, cultural, entre outras). Pesquisadores da área da surdez (Góes, 2002; Lacerda, Albres, \& Drago, 2013; Lodi, 2013; Skliar, 1997; Slomski, 2010), cientes da essencialidade da Língua de Sinais, apontam os conflitos vivenciados pelos surdos nas situações de inclusão escolar, dadas as razões concernentes à forma peculiar de comunicação e de compreensão do mundo. Eles alertam que a surdez traz implicações referentes à construção identitária, pois os surdos são bilíngues. Nesse sentido, um dos maiores desafios impostos a esse alunado, diante de uma escola pensada e programada para os ouvintes, diz respeito a sua escolaridade. Enfim, como aprender?

Para Santana e Bergamo (2005), a Língua de Sinais é o fator que distingue o indivíduo surdo do ouvinte, aparecendo como elemento central para o desenvolvimento (também acadêmico) daquele. Entretanto, essa mesma língua se constitui, contraditoriamente, como fator de discriminação do surdo na sociedade majoritária. Desse modo, não raras vezes, o surdo vivencia situações de fracasso dentro da escola, resultante das relações estabelecidas com a maioria ouvinte e dos embates desdobrados das questões linguísticas (Lacerda, 2006a).

Por isso, afirmam os pesquisadores (Ribeiro, 2013; Silva, 2014), as escolas devem assegurar o trabalho pautado na Libras e nas implicações dela para a aprendizagem. Essa língua traz impactos para o modo de constituição do surdo e diz respeito, centralmente, aos aspectos referentes à cultura surda (Dizeu \& Caporalli, 2005). Se nos estabelecimentos 
de ensino, porventura, tais aspectos forem desprezados, a relação do surdo com os pares pode gerar conflitos de ordens psicológicas, pedagógicas e sociais, gerando o fracasso escolar desses sujeitos (Ribeiro, 2014). Quadros (2003), ao discutir essa situação, caracteriza a sensação de alguns estudantes surdos em sala de aula: silenciados dentro do grupo. O silêncio, na verdade, representa o sentimento de vazio relatado por muitos surdos quando descrevem o resultado insatisfatório que conseguiram após anos frequentando uma escola (Lacerda, 2006b). A inclusão, a qualquer custo, negligencia questões fundamentais referentes à cultura, linguagem, dinâmicas (entre outros aspectos) de comunidades minoritárias pouco enaltecidas no processo educacional (Góes \& Lacerda, 2000). O problema central, sem dúvida, é a forma como a língua de sinais é compreendida e aceita pelos projetos educacionais(Silva, Silva, \& Silva, 2013).

Regulamentando a Lei 10.436, o Decreto $n^{\circ}$ $5626 / 2005$ instituiu a Libras como disciplina curricular obrigatória para cursos de formação de professores e optativa para os demais cursos de educação superior. Delimita-se, então, por meio do decreto, quem são as pessoas surdas, para fins de aplicação da Lei. Segue: "considera-se pessoa surda aquela que, por ter perda auditiva, compreende e interage com o mundo por meio de experiências visuais, manifestando sua cultura principalmente pelo uso da Língua Brasileira de Sinais - Libras" (Decreto n. 5626, 2005). O percurso entre a oficialização da Libras, como instrumento próprio de linguagem e identidade de pessoas surdas, e a implementação obrigatória na formação de professores, estimulou fortes debates sobre a possibilidade da criação de cursos superiores voltados para esse público. Como destaca Franco (2009), a Lei e o Decreto promovem o reconhecimento dessa modalidade linguística e são fundamentais para a discussão da Libras no cotidiano dos ambientes escolares.

Todos esses encaminhamentos relacionados à língua dos surdos, ocorridos nas últimas duas décadas, colaboraram para que a filosofia educacional baseada no bilinguismo obtivesse maior visibilidade na educação dessa comunidade (Kubaski \& Moraes, 2009; Lodi, 2013). Essa premissa está amparada na nota técnica $n^{\circ} 62$ de 8 de dezembro de 2011, em que o MEC esclarece sobre a organização da educação bilíngue nas escolas da rede pública de ensino, reafirmando apontamentos existentes no Decreto $n^{\circ} 5626 / 2005$.

O bilinguismo, no caso dos estudantes que não ouvem, se define como condição para inserção nos processos dialógicos do meio em que vivem. Ou seja, a partir do desenvolvimento primário, via Língua de Sinais, acessar e se apropriar dos elementos culturais produzidos pela sociedade, bem como o português, concebido como segunda língua. À luz dessa proposta, as políticas educacionais inclusivas devem assegurar o direito dos surdos de partilharem de sua língua nas escolas públicas de ensino regular (Lacerda, Albres, \& Drago, 2013; Lodi, 2013).

Sabe-se, no entanto, que o desenvolvimento de propostas de cunho bilíngue na esfera escolar tem sido um desafio constante para profissionais da educação, intérpre- tes e gestores escolares. Ainda que a escola disponibilize o intérprete que, de certa forma, permite ao surdo manter a comunicação pela Língua de Sinais, isso pode se restringir a uma "inclusão como território, como espaço, como concepção de uma escola em que a Língua de Sinais passe apenas pela tradução da língua oral” (Giordani, p. 97-98). Ou seja, o trabalho escolar em que essa língua representa apenas um instrumento pedagógico, descaracterizando-a como linguagem genuína em sua plenitude (Souza \& Lippe, 2012; Witkoski \& Baibich-Faria, 2010).

A dinâmica que tem ocorrido nas escolas públicas promove essa visão sobre a Língua de Sinais. Nas salas comuns, em que os professores ensinam em língua portuguesa, o surdo fica à mercê da interpretação (Silva, Silva \& Silva, 2014; Ribeiro, 2014). O trabalho escolar em Libras, portanto, é realizado, principalmente, nos atendimentos educacionais especializados, isto é, nas salas de recursos multifuncionais. Entretanto, não é atribuída em caráter prioritário para o ensino dos surdos, pois nessas condições ocorre de forma complementar ou suplementar, já que se trata da própria definição legislativa do AEE (Soares, 2013). Witkoski e Baibich-Faria (2010) apresentam um argumento indispensável para a compreensão do significado social da Língua de Sinais: "gata borralheira" em face à "cinderalidade" daquilo que é da maioria, ou seja, da língua oral” (2010, p. 340).

Essa situação se relaciona com as grandes transformações e embates ocorridos, ao longo do tempo, sobre a educação de surdos. Carvalho e Marinho (2007) salientam que as diferentes práticas pedagógicas foram oriundas da dicotomia entre o uso ou não da Língua de Sinais na sala de aula somadas aos outros elementos referentes à cultura surda, resultando em formas distintas de compreensão da educação para essa comunidade linguística. Nesse contexto, é importante saber como os profissionais que atuam na inclusão de surdos compreendem o papel da Língua de Sinais nesse processo.

\section{Os desafios pedagógicos atuais na construção das propostas bilíngues para a educação de surdos}

Os modelos pedagógicos pautados no bilinguismo se fortaleceram na última década no Brasil. O bilinguismo é responsável por transformações na concepção ideológica sobre o que é ser surdo, que sucederam formas organizativas de ensino mais pertinentes a esse público (Fernandes \& Moreira, 2009; Skliar, 1997/2006). Por meio de diferentes modalidades de ensino e variadas interpretações sobre o que vem a ser bilinguismo, essa abordagem educacional aponta para composição de práticas educacionais que consideram a centralidade dos aspectos linguísticos e sociais para a cultura surda.

Inspiradas pelos debates emergentes por pesquisadores defensores do bilinguismo (Dizeu \& Caporali, 2005; Fernandes \& Moreira, 2009; Lacerda, 2006a e b), as políticas educacionais inclusivas atuais pretendem assegurar o direito dos surdos de partilharem de sua língua nas escolas 
públicas de ensino regular. Há deliberações específicas (Decreto n. 5626, 2005; Lei n. 10436, 2002) sobre a formação de professores bilíngues, instrutores surdos e intérpretes de Libras, no entanto a estruturação do bilinguismo nas práticas pedagógicas, mais precisamente as questões metodológicas, ainda se delineiam como um desafio (Silva, Silva, \& Silva, 2014).

Segundo Goldfeld (1997/2002) e outros pesquisadores, apesar de não haver unanimidade na aplicação do bilinguismo na esfera educacional, observam-se dois formatos de materialização dessa filosofia: o primeiro aponta para a aprendizagem da Língua de Sinais e da língua oral/auditiva majoritária com a alfabetização na Língua de Sinais a posteriori. O segundo, advogado por Sánchez (1999) e outros autores, descarta a necessidade de aprendizagem da língua oral, priorizando que o surdo adquira a Língua de Sinais e a língua oficial na modalidade escrita. Porém, atualmente (Ribeiro, 2014; Monteiro, 2014), coexistem diferentes modelos para a educação bilíngue dos surdos. Por isso, é importante evidenciar como as ações orientadas sob a ótica bilíngue têm sido sistematizadas no cotidiano dos estudantes.

Nesse sentido, Quadros (2006) descreve a importância de se garantir, na matrícula desses estudantes, a oferta de intérpretes. Entretanto, a autora alerta que a presença desse profissional não fornece todas as condições que o aluno surdo requer. A pesquisadora afirma que o trabalho de interpretação circula entre duas línguas, partindo da tradução do conteúdo em Português para a Língua de Sinais, que é, portanto, secundária no processo. Isto é, as estratégias de ensino são pensadas, a priori, na língua da nação, presumindo que: a) a tradução para a Libras é o suficiente para a aprendizagem e b) a presença de intérprete significa resguardar o direito linguístico dos surdos.

Segundo Quadros (2006), o intérprete representa um mecanismo legal das políticas de inclusão para manter os estudantes surdos nas escolas regulares, considerando que o ensino ideal para os surdos deveria ocorrer em escolas que utilizassem a Libras, como primeira língua. Contudo, mesmo com o auxílio do intérprete, incoerências ainda permeiam a vida escolar de crianças e jovens surdos. A barreira comunicativa não se delineia como fator único de limitação para a escolarização desse grupo.

Lacerda (2006b) evidencia a experiência solitária vivenciada pelos surdos nas escolas inclusivas quando (somente) acompanhados por intérpretes. Muitas vezes, os surdos não estabelecem relações efetivas com os demais pares escolares, pois professores, companheiros de classe e funcionários são ouvintes. Esse fator compromete o aprofundamento de suas relações, que são resumidas em trocas básicas de informações, por conta da não compatibilidade linguística.

Assim sendo, o papel desempenhado pelo intérprete se delineia como ponto chave, já que ele é o elo entre o surdo e o universo escolar majoritário. Lacerda (2006b) aponta a responsabilidade dada a este profissional, que ultrapassa a prática de traduzir os conteúdos, tendo em vista o objetivo de certificação sobre a compreensão do aluno surdo. Nes- ses termos, é necessária uma sintonia entre a interpretação e o trabalho dos outros profissionais da equipe envolvidos no processo educativo, com a finalidade de promover não só a escolarização, mas garantir a aceitação do aluno surdo na sala de aula e no universo escolar.

A proposta de educação bilíngue, advogada pelos estudiosos da vertente dos Estudos Culturais da Surdez (Perlin, 1998/2006; Quadros, 2012; Skliar, 1997/2003), por exemplo, aponta para a capilaridade dessa abordagem; uma filosofia que se desdobra nos âmbitos da questão metodológica, linguística, psicolingüística e pedagógica.

Atualmente, inúmeros autores (Lacerda, Albres, \& Drago, 2013; Merselian \& Vitaliano, 2011) e comunidade surda discutem a respeito da escola ideal para a implantação efetiva do bilinguismo, considerando que o modelo vigente na escola inclusiva, que se funda na participação do intérprete, tem sido frequentemente questionado por não oportunizar condições coerentes à aprendizagem e ao desenvolvimento desses estudantes. Fatores relacionados à proficiência dos professores em Libras, ao trabalho escolar pautado na língua e à cultura surda são elementos defendidos pelos surdos.

Nessa linha Lacerda, Albres e Drago (2013) analisaram a política educacional de alunos com surdez e seu impacto em escolas do município de São Paulo. Esse município possui escolas bilíngues exclusivas para esse público, além da escola regular inclusiva, fato que indica uma tentativa de aproximação sensível aos desejos da comunidade surda² . Em contrapartida, o estudo enfatiza que, independentemente do tipo de escola, uma educação de qualidade para os surdos requer condições concretas de implementação das políticas governamentais para atender as especificidades desse público - isto é, uma escola com planejamento de ações pedagógicas coerentes com os pilares de uma educação bilíngue.

O tratamento dos aspectos pedagógicos tem sido reiteradamente discutido nos estudos concernentes a esse tema, contribuindo para a reflexão e proposição de novos caminhos. O papel do professor, do intérprete, modos de promoção da Língua de Sinais na escola, bem como o desenvolvimento de metodologias específicas para a aprendizagem dos surdos são aspectos sinalizados em recentes esforços investigativos (Campello, 2007; Lebedeff, 2010; Sá, 2011).

Campello (2007), por exemplo, descreve o trabalho de uma professora surda que se beneficia da pedagogia visual nos processos de ensino-aprendizagem, traduzindo, de forma geral, a importância de uma reformulação curricular e de uma didática que explore não apenas a imagem, mas uma "semiótica visual na prática educacional cotidiana" ( $p$. 130). A investigação de Campello (2007) foi resultante do projeto "Educação de Surdos: professores surdos, professo-

2 A comunidade surda requereu a criação de escolas bilíngues exclusivas para surdos. Esse desejo está expresso no documento "A Educação que nós surdos queremos" e amparado legalmente no Decreto 52.785, de 2011. 
res bilíngues e intérpretes de línguas de sinais" (2003-2008), desenvolvido na Universidade Federal de Santa Catarina.

Contudo, apesar das experiências bilíngues supracitadas, ainda não há uma diretriz ou um modelo já consolidado sobre como deve ser a educação de surdos; a sensação dos professores, de acordo com Santos (2011), é de limitações na formação para o atendimento desse alunado frente à sua peculiaridade linguística.

Esses aspectos, que merecem ser considerados para efetivar um ensino bilíngue de qualidade para os surdos, colocam em destaque todos os profissionais que atuam com esses alunos nas escolas. A partir do contexto de múltiplas facetas e posicionamentos ideológicos contraditórios sobre a inclusão de surdo, o objetivo desse trabalho é analisar os posicionamentos dos diversos agentes profissionais atuantes na escola frente à educação dos surdos. Afinal, o que eles dizem a respeito do papel da Língua de Sinais no processo de escolarização dos surdos?

\section{Método}

A pesquisa foi baseada na construção de dados organizados a partir de entrevistas, com ênfase para análise dos significados produzidos pelos participantes acerca do processo de inclusão dos surdos e seus desafios. Dessa forma, a reflexão produzida entre pesquisador e entrevistado compôs um material importante para a análise da palavra e dos sentidos atribuídos a ela, considerando as condições materiais nas quais ela é produzida.

A entrevista semiestruturada foi pautada na formulação de um roteiro geral para orientar a pesquisa. No entanto, a atuação do investigador não ficou restrita às perguntas pré-estabelecidas (Manzini, 2004). Ela abrangeu também o próprio contato com o entrevistado e as reflexões e análises provenientes desse encontro, permitindo a reelaboração de hipóteses relacionadas ao tema de pesquisa.

As entrevistas reunidas para a presente pesquisa formaram um texto no qual a palavra é contemplada como unidade categorial de análise. Por esse viés, apreende-se a circularidade dos discursos dos participantes permitindo a compreensão do jogo de sentidos comuns do processo de produção e interpretação do conhecimento científico, que na composição desse trabalho é articulado as dinâmicas culturais em que os sujeitos estão imersos (Góes \& Cruz, 2006).

\section{Caracterização do campo}

O contexto de investigação foi uma escola inclusiva de ensino médio, da rede pública, do Distrito Federal, que possui aproximadamente quarenta alunos surdos matriculados. Tal escola fica localizada em Brasília,naAsa Sul, e é reconhecida pelo atendimento especializado aos alunos incluídos no grupo de deficiências sensoriais: surdez e surdo-cegueira. Por ser um polo de atendimento importante para os surdos, do DF, optou-se por fazer a investigação nesse estabelecimento de ensino.

\section{Participantes da Pesquisa}

Com o intuito de entender os posicionamentos dos diferentes personagens que participam, direta ou indiretamente, do processo de inclusão educacional dos surdos, o trabalho de campo estruturou-se a partir dos profissionais da escola que atuavam com surdos. Para tanto, participaram da investigação oito profissionais da equipe escolar: o supervisor pedagógico, a coordenadora da área de humanas, o coordenador da área de exatas, a coordenadora de linguagens e códigos, a diretora, o professor de português como segunda língua, a professora da sala de recursos multifuncionais e o intérprete de Libras.

\section{Procedimentos de Construção dos Dados}

As entrevistas realizadas neste estudo foram vídeogravadas em uma sala isolada nas dependências da escola, tendo uma duração média de 120 minutos cada. Optou-se por realizá-las duas vezes com cada participante. A pesquisa foi subdividida em três momentos: a) reunião preliminar com o grupo de profissionais participantes; b) realização da primeira etapa de entrevistas com os profissionais (individualmente); e c) a segunda etapa de entrevistas com os profissionais.

No campo buscou-se reconhecer, por meio de entrevistas semiestruturadas, as percepções dos profissionais sobre: a) conceitos acerca da surdez e Língua de sinais, b) a inclusão de surdos e c) os desafios da inclusão educacional dos surdos para a escola.

Todo o processo ocorreu entre o primeiro e o segundo semestre de 2013. Ao final da coleta de dados, as videogravações foram integralmente transcritas, resultando um diário de campo analisado cuidadosamente na tessitura deste trabalho.

\section{Resultados e Discussão}

Das análises depreendeu-se um eixo importante acerca dos posicionamentos dos profissionais envolvidos na inclusão educacional do surdo no que tange à centralidade (ou não) da Língua de Sinais no processo de escolarização desse alunado.

É importante evidenciar que, para os profissionais investigados, a comunicação é central para discutir a inclusão do surdo. Nesse contexto, a visão sobre a surdez está intrinsecamente ligada aos modos como eles compreendem os alunos e, de forma mais específica, o significado da Libras e do bilinguismo como fio condutor dos processos de escolarização dos estudantes. 
Uma educação sob os moldes bilíngues considera a Língua de Sinais como fator central para o processo de escolarização, pois a língua é um elemento basilar da identidade cultural dos surdos e da comunidade à qual eles pertencem. Por isso, muitos autores (Lodi, 2013; Kelman \& cols., 2011) advogam a favor do bilinguismo, como discutido anteriormente, pois, tal modelo, parte do respeito à língua do surdo e às especificidades advindas dela.

Nesse sentido, Vitória (intérprete de Libras) apresenta em seus comentários fortes críticas sobre o atual modelo de escola inclusiva no Distrito Federal, tendo em vista os pilares do bilinguismo:

O princípio de uma escola bilíngue é uma sala de aula em que há comunicação em duas línguas... Aqui, em Brasília, a gente tem umas três ou quatro escolas bilíngues inglês/ português. As crianças que estudam nessas instituições estão em um ambiente bilíngue no qual o português não é a primeira língua. A escola inteira se comunica pela língua inglesa, as aulas são ministradas em inglês e o ambiente é de imersão nessa língua.

A cultura daquela língua alvo é respeitada em todos os seus aspectos porque acredita-se que o aprendizado da língua venha pela imersão na cultura. Comparando com o bilinguismo para os surdos, podemos compreender que a origem das falhas está na falta de imersão na cultura surda, gerando uma visão deturpada sobre a Língua de Sinais e sobre o aluno surdo. Isso ocorre porque os profissionais que trabalham na área entram, fazem um curso básico e, aí, passam por uma entrevista em um determinado setor que os qualifica como eficientes em Libras e, por conseguinte, prontos para o trabalho escolar com os meninos...

O erro mais grave é justamente a ausência de discussões mais profundas. Comigo aconteceu diferente... Quando eu tive o primeiro contato com uma pessoa surda, eu me senti mal, o problema estava em mim, eu não sabia me comunicar com a aluna surda... Pensei: "ela não pode vir a minha língua, mas eu posso ir à língua dela”. A minha primeira percepção foi inocente e infantil. Eu vi uma pessoa que falava uma outra língua e consegui visualizar que ela tinha uma forma de sere de se comunicar, ela estava se comunicando, eu é que não abarcava isso. Então, eu fui aprender, buscar esse domínio do visual-espacial.

Vitória (intérprete de Libras), ao discorrer sobre a implementação do bilinguismo na escola alerta para questões fundamentais: a) a importância dos profissionais saberem a Língua de Sinais e b) o projeto escolar bilíngue que respeite igualmente as duas modalidades linguísticas adotadas (oral e sinalizada). Além disso, ela faz uma denúncia sobre como a formação dos profissionais em Libras está sendo conduzida, especificamente, no DF. Vale ressaltar que a proficiência linguística dos educadores, somadas ao capital cultural, refletem diretamente em suas possibilidades criativas diante das exigências pedagógicas, que sob o prisma bilíngue per- passa em duas comunidades com línguas e culturas distintas que devem ser de domínio dos educadores.

Considerando a essencialidade da Língua de Sinais, Sandra (professora da sala de recursos) acrescenta:

A Libras é a língua deles mesmo! Nós, ouvintes, precisamos entender melhor a Libras para podermos nos comunicar. Enquanto tiver essa barreira de comunicação da nossa parte para eles, eles vão ficar sempre acuados, esperando alguém chegar perto, sem aquela força de se expressar. Apesar da língua deles abranger tudinho. Mas nós somos a maioria e a maioria oprime... oprime a língua deles.

Witkoski (2009) explica que, tradicionalmente, os surdos vivem sujeitados a uma posição de menos valia diante do ouvinte, principalmente, decorrente das representações ouvintistas (como discutido no eixo A). Tal lógica legitima a palavra falada e tudo que pertence à cultura majoritária ouvinte de modo imperativo, denotando nas esferas educativas, práticas pedagógicas normalizadoras (à minoria desviante do padrão) e a culminância do preconceito nas dinâmicas escolares cotidianas. Desse modo, a língua e as expressões surdas, por exemplo, são questionadas e observadas de modo aversivo (frequentemente adjetivadas como manifestações estranhas). Ou seja, as especificidades e diferenças tornam-se símbolo de opressão.

Nessa linha, Vera (diretora) explica:

Eu imaginava... por achar que a Língua de Sinais não é uma linguagem, que a leitura labial, colocar o aparelho etc. fosse uma questão interessante, importante para o surdo... Mas eu li, tenho lido muito sobre o dano que é o aparelho para o surdo que começa a ouvir... eu não sabia! Implica até questões psicológicas. No primeiro momento, a gente pensa assim: "não, só basta ouvir!" Mas isso não é verdade. O ruído vai começar a gerar um estresse nele. A gente sabe dessa situação do aparelho, das cirurgias, do implante. Depois, eu vi o tanto que foi traumático; já li relatos de surdos falando o tanto que foi traumático a insistência de que ele tinha que aprender a linguagem labial, ou a linguagem escrita, a linguagem normal que a gente conhece. E, aí, eu achei, aí, é uma conclusão minha: que a Língua de Sinais é a que menos fere psicologicamente o surdo. E já que a ciência, ao que parece, tá provando que é uma linguagem mesmo, que ela atinge diversas esferas do cérebro responsáveis pela linguagem, então, eu acho que é o elemento mais natural para a gente lidar com o surdo.

De um modo geral, a discussão sobre a Libras na escola traz consigo os fundamentos nos quais os profissionais se calcam, principalmente, no que se refere à língua e a história do surdo. Como visto em Sacks (2010), a língua dos surdos é uma extraordinária criação humana frente aos desafios derivados do modo como o mundo é, aparentemente, para eles, os criadores da Língua de Sinais: silencioso e/ou com poucos ruídos. 
Considerando o componente visuo-espacial particular desta língua (e outros elementos decorrentes da cultura surda), já discutidos anteriormente, os profissionais se posicionam contraditoriamente acerca dos modos como o trabaIho pedagógico é desenvolvido, eles parecem saber que o trabalho com os surdos exige transformações pedagógicas, especialmente, em função da questão linguística, mas na prática, como pode ser visto acima, ainda há entraves para o desenvolvimento de: a) uma pedagogia diferenciada e b) exploração das dinâmicas escolares partindo da Língua de Sinais.

Destaca-se o fato investigativo, pois muitos dos entrevistados, mesmo cientes da importância desta Libras para a vida escolar do surdo, conduzem seus discursos em direção à Língua Portuguesa e pautam suas práticas escolares, de um modo geral, nesta língua. Daí decorre o problema de evasão e fracasso escolar do surdo (Quadros, 2006; Witkoski, 2009).

Maria (coordenadora de linguagens e códigos), por exemplo, pouco se refere à Libras ao narrar o dia-a-dia escolar. Ela argumenta que tal língua precisa existir na escola unicamente em razão da dificuldade e inabilidade dos estudantes surdos para aprender a Língua Portuguesa. Ela narra:

Pedagogicamente falando, eu acho que o professor regente, quando ele tem um pouco mais de conhecimento de Libras, ele também vai perceber que o vocabulário do surdo é muito mais reduzido que o vocabulário de um ouvinte. Então, se o professor regente tem conhecimento de Libras, ele também vai saber fazer com mais perfeição, essas adequações que ele faz. Por exemplo, na prática, o aluno surdo não tem domínio de pronome, preposição, artigo, da Língua Portuguesa, então, o professor quando vai ler o texto de um aluno surdo, ele já vai ter o olhar mais compassivo em relação àquela necessidade que o surdo tem, ou aquela limitação que o surdo tem, é só nesse sentido, que a Libras auxilia entendeu?

Esta visão parece ser disseminada entre os profissionais entrevistados, considerando que João (professor da sala de recursos), Graça (coordenadora de humanas) e Tim (coordenador de exatas) apresentam em seus relatos críticas sobre o modo como a Língua de Sinais é incorporada pelo surdo e pelos profissionais da sala de recursos. Eles alegam que os surdos deveriam se esforçar mais para compreender a língua da maioria e, desta maneira, descartar as amarras consequentes do uso da Língua de Sinais: por exemplo, ser dependente de um intérprete. Em face disso, está o conceito que eles têm a respeito da Libras: uma ferramenta de acesso, um instrumento, como pode ser observado no depoimento de Tim (coordenador de exatas):

Eu vejo a Libras para o surdo da seguinte forma... a gente tem que criar um meio de comunicação, estabelecer uma forma de linguagem entre pessoas ouvintes e pessoas surdas. E o que a gente tem hoje, e que eu acho que é de grande valia, é a Libras. Vamos pensar em uma situação em que não existisse essa linguagem, aí eu acredito que a comunicação seria muito mais dificultada. Eu acho que é um recurso a mais positivo para que essa comunicação aconteça. Como eu estou inserido em um contexto em que a Libras é essa linguagem, eu não conseguiria imaginar uma outra forma de comunicação. Eu acho que é bastante positiva essa linguagem para a comunicação entre os ouvintes e os surdos, os surdos e outros surdos.

Inicialmente o relato de Tim (coordenador de exatas) traz considerações positivas acerca da Língua de Sinais, entretanto, trechos (como o grifado) traduzem sutilmente o significado da Libras: um recurso ou espécie de ponte entre surdos e ouvintes. Os comentários dele refletem uma interpretação simplista sobre a função da Libras, de modo que parece não compreendê-la em sua plenitude, pois, não se trata de uma ferramenta para auxiliar a comunicação, ela é a primeira língua do surdo.

Nessa linha, Maria (coordenadora de linguagens e códigos) defende que a Libras é essencial para a socialização do surdo, entretanto, não deve ser o foco. Ela afirma que os surdos precisam dedicar-se para aprender o Português porque é uma demanda imediata nos processos de ensino e aprendizagem. Todavia, ela deixa explícito que a Libras não é uma língua que capacita o surdo. Ela comenta:

O fato do aluno surdo só ter domínio de Libras e não ter domínio extremo sobre a Língua Portuguesa é complicado. Tudo bem... nem os ouvintes têm exatamente esse domínio de Língua Portuguesa e para os surdos é muito mais difícil. Se o aluno que é surdo tem esse domínio estreito ou resumido de português, ele também tem um pouco mais de dificuldade, mas é uma questão de correr atrás, de aprender... A parte de Libras vem para facilitar. $O$ acesso a Libras facilita muito mais no universo social do que no universo cognitivo. Então, eu acho que o acesso de Libras para os ouvintes ajudaria muito mais na socialização desse surdo, do surdo com o ouvinte, do que no aspecto cognitivo. Entendeu? Então, seria só nesse sentido, de alcançar um pouco mais.

O relato de Maria (coordenadora de linguagens e códigos) sugere que a Libras não é capaz de propiciar o desenvolvimento cognitivo por se tratar de um código distinto de uma língua genuinamente completa. Ela afirma: "Se o aluno que é surdo tem esse domínio estreito ou resumido de Português, ele também tem um pouco mais de dificuldade, mas é uma questão de correr atrás, de aprender... A parte de Libras vem para facilitar". Por esse motivo, contra argumenta todas as pressuposições de um trabalho pedagógico que a estabeleça como língua de instrução.

Seguindo esse raciocínio, Igor (supervisor pedagógico) relata que o uso da Libras é necessário para a inclusão, mas aponta que a falta de universalidade cria empecilhos para o processo educativo. Ele adverte: 
Tem alunos surdos que estão extremamente defasados, praticamente analfabetos, tamanha é a pobreza da Ling... dos códigos que eles têm. Então, isso dificulta muito o aprendizado dele, porque como o universo de língua dele é muito pequeno, é muito restrito, e você chega com um monte de informações para esse menino, ele não consegue absorver um terço dessas informações, entendeu? Os intérpretes, por mais que eles queiram ajudar, eles ficam limitados por causa dessas linguagens que são diferentes.

As críticas tecidas por Igor (supervisor pedagógico) trazem duas questões que comumente são discutidas em investigações sobre as línguas de sinais em interface com os processos de escolarização do surdo: a) a aprendizagem tardia da língua pelos surdos (considerando que a maioria das crianças nasce em famílias de pais ouvintes) e b) a estrutura das línguas de sinais (Lebedeff, 2010).

No caso específico dos estudantes surdos, narrados por ele, depreende-se que ainda estão se apropriando da Língua de Sinais, no entanto, para Igor (supervisor pedagógico) o problema referente à alfabetização dos surdos está na Libras, ou seja, o educador acredita que tal língua é um problema. Ele evidencia que ela apresenta uma estrutura pobre, reduzida e não universalizada, atrasando o desenvolvimento acadêmico dos estudantes, como fica claro em sua fala: "Tem alunos surdos que estão extremamente defasados, praticamente analfabetos, tamanha é a pobreza da Ling... dos códigos que eles têm".

Quadros (1997) explica que a Libras, assim como todas as línguas de sinais, possuem estruturas completas e distintas das línguas orais, porém apresenta fenômenos semelhantes, por exemplo, as variações linguísticas. A autora relata que as línguas estão articuladas com as comunidades nas quais são faladas/sinalizadas, daí, justifica-se a importância do desenvolvimento linguístico entrelaçado com o cultural, no qual desdobram-se os modos específicos de representação da língua (expressões e gírias). Não há, portanto, Língua que se delineie universal, elas variam de acordo com a comunidade, o país e região do país em que são utilizadas.

O posicionamento de Igor (supervisor pedagógico) e de alguns entrevistados refletem o pouco conhecimento acerca, não apenas da Libras, mas do mundo dos surdos, de um modo geral. Em meandros, seus discursos se voltam para a defesa de uma educação padronizada sob a ótica do aluno ouvinte, em que, contraditoriamente, fala-se sobre as especificidades advindas dos alunos. Porém, na prática, a pedagogia, a língua e a cultura excluem aqueles que destoam do padrão.

Tal realidade pode ser vista a partir do depoimento de Graça (coordenadora de humanas) ao discutir o modo como percebe a Libras no espaço escolar. Ela argumenta que o surdo não pode se ater a um universo linguístico não compartilhado com a maioria, e que, por isso, a escola deve insistir e forçar na aprendizagem via Português (na qualidade de primeira língua) pois, segundo ela, isso incluirá o surdo verdadeiramente na sociedade. Ela (coordenadora de humanas) problematiza:
O mundo não fala Libras, ele (referindo-se ao aluno surdo) está no mundo, mas o mundo não fala Libras. Eu não falo Libras, eu uso o básico de comunicação. Mas ele não está incluído? Além disso, ele não tem o entendimento da língua portuguesa. Ele não tem e ele não faz. Então, ele não faz o entendimento, não entende as coisas. Eu saberia me comunicar melhor com ele, formular o texto de um jeito mais pertinente a ele, mas ele não tem, às vezes, o mínimo de entendimento. Até pela leitura, até pela escrita. Então, você fica rendido... sem saber o que fazer. Porque ele não tem o pensamento, porque a formação de conhecimento dele é diferenciada e o mínimo que entende é em Libras. E seu desenvolvimento não chega a ser tão próximo (ao do ouvinte). Ele pode ser diferenciado, mas eu tinha que caminhar para uma proximidade maior. Porque o nosso mundo fala português, fala a língua portuguesa. Então, ele deveria ser capaz de se comunicar com um bilhetinho, com qualquer coisa, como é que ele se comunica lá fora?

Entre outros fatores, Graça (coordenadora de humanas) alega que não há incentivo para o desenvolvimento acadêmico do surdo pela Libras, por ser uma língua não reconhecida e severamente combatida por representantes da comunidade escolar. Ela justifica tais argumentos:

Tem pais que nem gostam que os meninos aprendam Libras. Chegam meninos aqui sem Libras no ensino médio, que a mãe não gosta, não aceita e não quer que eles aprendam. Muito engraçado o posicionamento dela: "ah, meu filho parece um macaco". Assusta? Eu também me assustei: "Eu não quero que meu filho fique parecendo um macaquinho"... porque eles falam com as mãos e isso chama a atenção né?

Apresentar comentários feitos por uma mãe de aluno surdo parece ser o mecanismo utilizado por Graça (coordenadora de humanas) para apresentar preceitos sociais acerca da Libras, do surdo e, mais confortavelmente, tecer críticas sobre as expressões faciais e os movimentos corporais que constituem os sinais. Ela revela, portanto, que as peculiaridades dos surdos (advindas de sua cultura) são vistas com estranhamento e aversão, não obstante, a manifestação da Libras é percebida como uma espécie de trejeito ou gestos cômicos que despertam olhares negativos.

Os posicionamentos de alguns profissionais entrevistados revelam que ainda há bastante preconceito relacionado à Libras, normalmente, apoiado em concepções pouco fundamentadas. Tais profissionais negam constantemente a validade de um ensino que priorize a Libras e questionam o modo como os profissionais da sala de recursos se apropriam exclusivamente de tal língua, apesar de permanecerem apresentando severas dificuldades para conduzir o processo educativo dos surdos, seguindo o modelo que acreditam ser $\mathrm{o}$ ideal, pois prioriza a oralidade. Por outro lado, os depoimentos anunciam a necessidade de discussões mais aprofundadas no que tange à família e o impacto de suas concepções, especificamente, no tocante à Libras e à educação do surdo. 


\section{Considerações Finais}

Os posicionamentos dos profissionais envolvidos na inclusão educacional de surdos trouxeram à tona questões sobre as demandas culturais, linguísticas, pedagógicas e o impacto desses elementos no desenvolvimento bicultural do surdo. Tal debate está situado nas interfaces entre Psicologia e Educação, haja vista a singularidade dos processos simbólicos dos estudantes (que se constituem na Língua de Sinais) e o reflexo dessa condição no campo educativo.

A pesquisa revelou o modo como a inclusão educacional tem sido conduzida, considerando os processos de formação dos profissionais do DF, que merecem atenção e discussões mais aprofundadas. Percebeu-se que há uma lacuna na formação conceitual sobre a surdez, o surdo e a Língua de Sinais nos quais estão situados e marginalizados os maiores problemas de ordem pedagógica.

Como visto na análise, os profissionais conhecem as demandas para a inclusão educacional dos surdos, no entanto, desenvolvem práticas pouco fundamentadas nas necessidades apresentadas pelo público, por isso enfrentam severas dificuldades para ensinar. Tal situação indica incongruências mais amplas relacionadas ao modo como o propósito político da inclusão foi apregoado e como os educadores foram preparados para materializá-lo na escola.

Os fatores levantados nesse empreendimento investigativo refletem a necessidade de revisão das práticas educacionais e as condições às quais estão subjugadas a inclusão dos estudantes. A formação bicultural e bilíngue de surdos, portanto, precisa ter centralmente considerada a importância da Língua de Sinais, mas deve também levar em consideração outros aspectos importantes da prática pedagógica, a saber: a pedagogia da imagem, alternativas estratégicas para o desenvolvimento pedagógico, a formação de educadores surdos etc. $O$ desprezo e a negligência à essas singularidades dentro da escola comprometem as possibilidades de aprendizagem dos surdos.

Destaca-se a urgente necessidade de aprofundamento de estudos acerca dessas questões, para auxiliar na compreensão e encaminhamento de propostas que, de fato, venham a modificar o panorama educacional dos alunos surdos. Até o momento, apesar da legislação e do posicionamento favorável de profissionais da área, a inclusão não se concretiza na prática. Tais estudos devem ser multidisciplinares, a fim de que sejam conhecidas as aspirações e os impactos nos atores desse processo: alunos e profissionais da escola.

\section{Referências}

Campello, A.R. S. (2007). Pedagogia Visual/Sinal na Educação dos Surdos. Em R. M. Quadros \& G. Perlin (Orgs.), Estudos Surdos II. (pp. 100-131). Petrópolis, RJ: Arara Azul.

Carvalho, O.L.S. \& Marinho, M. L. (2007) Contribuições da lexicografia ao contexto educacional bilíngüe de surdo. Em H. M. M. Lima-
Salles (Org.), Bilingüismo dos surdos: questões lingüísticas e educacionais. (pp.119-142).Cânone Editorial.

Decreto n. 5.626, de 22 de dezembro de 2005 (2005). Regulamenta a Lei $n^{\circ}$ 10.436, de 24 de abril de 2002, que dispõe sobre a Língua Brasileira de Sinais - Libras, e o art. 18 da Lei $n^{\circ}$ 10.098, de 19 de dezembro de 2000. Recuperado: 19 out. 2014. Disponível: http://www.planalto.gov.br/ccivil_03/_ato2004-2006/2005/decreto/ d5626.htm.

Dizeu, L.C.T.B. \& Caporali, S.A. (2005). A Língua de Sinais constituindo o surdo como sujeito. Educação \& Sociedade, 26(91), 583-597.

Fernandes, S. \& Moreira, L.C. (2009). Desdobramentos politicopedagógicos do bilinguismo para surdos: reflexões e encaminhamentos. Revista de Educação Especial, 22 (34), 225236.

Franco, M. (2009). Educação superior bilíngue para surdos: o sentido da política inclusiva como espaço da liberdade: primeiras aproximações. Revista Brasileira de Educação Especial, 15(1), 15-30.

Garcia, R.M.C. (2013). Política de educação especial na perspectiva inclusiva e a formação docente no Brasil. Revista Brasileira de Educação,18(52), 101-119.

Giordani, L. F. (2004). Representações culturais da escrita: letramentos e educação de jovens e adultos surdos. Anais do Seminário de Pesquisa em Educação da Região Sul. Curitiba: Seminário de Pesquisa em Educação da Região Sul.

Góes, M. C. R. \& Cruz, M. N. (2006). Sentido, significado e conceito: notas sobre as contribuições de Lev Vigotski. ProPosições, 17(2), $31-45$.

Góes, M. C. R. (2002). Linguagem, surdez e educação (3a ed.). Campinas, SP: Autores Associados.

Góes, M. C. R. \& Lacerda, C. B. F. (2000). Surdez: processos educativos e subjetividade. São Paulo: Lovise.

Goldfeld, M. (2002). A criança surda: linguagem e cognição numa perspectiva sociointeracionista. ( $3^{\mathrm{a}}$ ed.). São Paulo: Plexus Editora. (Trabalho original publicado em 1997).

Instituto Nacional de Estudos e Pesquisas Educacionais Anísio Teixeira, Ministério da Educação [INEP/MEC] (2013). Dados do Censo Escolar de Educação Básica. Disponível: http://portal.inep. gov.br/basica-censo.

Kassar, M.D.C.M. (2011). Educação especial na perspectiva da educação inclusiva: desafios da implantação de uma política nacional. Educar em Revista, 41, 61-79.

Kelman, C.A., Silva, D.N.H., Amorim, A.C.F., Monteiro, R.M.G., \& Azevedo, D.C. (2011). Surdez e família: facetas das relações 
parentais no cotidiano comunicativo bilíngue. Brasília: Linhas Críticas.

Kubaski, C.\& Moraes, V.P. (2009). O bilingüismo como proposta educacional para crianças surdas. Em IX Congresso Nacional de Educação-EDUCERE - III Encontro Sul Brasileiro de Psicopedagogia (p. 3415). Paraná: PUCPR.

Lacerda, C.B.F. (2006a). A inclusão escolar de alunos surdos: o que dizem alunos professores e intérpretes sobre esta experiência. Cadernos CEDES, 26 (69), 163-184.

Lacerda, C. B. F. (2006b). A cultura surda e os intérpretes da Língua de Sinais. Revista Educação temática digital, 7(2), 135-143.

Lacerda, C.B.F. (2007). O que dizem/sentem alunos participantes de uma experiência de inclusão escolar com aluno surdo. Revista Brasileira de Educação Especial, 13(2), 257-280.

Lacerda, C.B. F., Albres, N. A., \& Drago, S.L.S. (2013). Política para uma educação bilíngue e inclusiva a alunos surdos no município de São Paulo. Educação e Pesquisa, 39(1), 65-80.

Lebedeff, T. (2010). A educação dos surdos na região do planalto médio rio-grandense: uma problematização das condições lingüísticas e de escolarização. Anais da $33^{a}$ Reunião Anual da ANPED "Educação no Brasil: O balanço de uma década". Caxambu: ANPED.

Lei n. 10.436, de 24 de abril 2002(2002). Dispõe sobre a língua brasileira de sinais - Libras - e dá outras providências. Brasília: Presidência da República. Recuperado: 17 out. 2014. Disponível: http://www.planalto.gov.br/ccivil_03/Leis/2002/L10436.htm.

Lodi, A.C.B. (2013). Educação bilíngue para surdos e inclusão segundo a Política Nacional de Educação Especial e o Decreto no 5.626/05. Educação e Pesquisa, 39(1), 49-63. Recuperado: 15 set. 2014. Disponível: ttp://www.scielo.br/scielo.php?script=sci_ arttext\&pid=S1517-97022013000100004\&Ing=en\&tIng= pt.10.1590/S1517-97022013000100004.

Manzini, E.J. (2004) Entrevista semiestruturada: análise de objetivos e de roteiros. Seminário internacional de pesquisa e estudos qualitativos em debate. Bauru: Universidade do Sagrado Coração.

Mendes, E.G. (2006). A radicalização do debate sobre inclusão escolar no Brasil. Revista Brasileira de Educação, 11(33), 387405. Recuperado: 17 set. 2014. Disponível: http://www.scielo.br/ scielo.php?script=sci_arttext\&pid=\$141324782006000300002\&ln $\mathrm{g}=$ en\&tIng=pt.10.1590/S141324782006000300002.

Merselian, K.T. \& Vitaliano, C.R. (2011). Análise das condições organizadas em uma escola para promover a inclusão de alunos surdos. Revista Lusófona de Educação. Recuperado: 20 out. 2014. Disponível: http://www.scielo.gpeari.mctes.pt/scielo. php?script=sci_arttext\&pid=S164572502011000300006\&lng=pt\& nrm=iso. Acesso em: 20 de outubro de 2014.
Michels, M.H. (2006). Gestão, formação docente e inclusão: eixos da reforma educacional brasileira que atribuem contornos à organização escolar. Revista Brasileira de Educação, 11(33), 406426.

Monteiro, R.M.G. (2014). Surdez e identidade bicultural: como nos descobrimos surdos?. Dissertação de Mestrado, Universidade de Brasília, DF.

Perlin, G. (2006). A Cultura Surda e os Intérpretes de Língua de Sinais. Revista Educação Temática Digital, 7(2), 136-147.

Quadros, R.M. (1997). Educação de surdos: a aquisição da linguagem.Porto Alegre: Artes Médicas.

Quadros, R.M. (2003). Situando as diferenças implicadas na educação de surdos: inclusão exclusão. Florianópolis: Editora Ponto de Vista.

Quadros, R.M. (2006). Políticas lingüísticas e educação de surdos em Santa Catarina: espaço de negociações. Cadernos Cedes, 26(69), 141-161.

Quadros, R. M. (2012). O “Bi” em bilinguismo na educação de surdos. Em A.C.B. Lodi \& C.B.F. Lacerda (Orgs.), Uma escola, duas línguas: letramento em língua portuguesa e Língua de Sinais nas etapas iniciais de escolarização (pp. 187-200, $3^{\text {a }}$ ed.). Porto Alegre: Mediação.

Ribeiro, C.B. (2011). As representações familiares acerca da surdez e suas implicações no processo de escolarização. Monografia de Graduação do curso de Pedagogia não publicada, Universidade de Brasília, Brasília, DF.

Ribeiro, C.B. (2013). Escolarização de surdos e desenvolvimento bicultural: trajetórias escolares de surdos: entre práticas pedagógicas e processos de desenvolvimento bicultural. Em Associação Brasileira de Psicologia do Desenvolvimento (org.). IX Congresso Brasileiro de Psicologia do Desenvolvimento. João Pessoa: Universidade Federal da Paraíba.

Ribeiro, C.B. (2014). Narrativas e processos de desenvolvimento bicultural: trajetórias escolares de surdos jovens e adultos. Dissertação de Mestrado não publicada, Universidade de Brasília, Brasília, DF.

Sá, N.R.L. (2011). Escolas e classes de surdos: opção políticopedagógica legítima. Em N.R.L. Sá (Org.), Surdos: qual escola? (pp. 17-62). Manaus: Editora Valer e Educa.

Sacks, O. (2010). Vendo vozes: uma viagem ao mundo dos surdos. São Paulo: Companhia das Letras.

Sánchez, C. (1999). La lengua escrita: esse esquivo objeto de lapedagogia para sordos y oyentes. Em C. Skliar (Org.), Atualidade da educação bilíngue para surdos. (pp. 35-47) Porto Alegre: Mediação. 
Santana, A.P. \& Bergamo, A. (2005). Cultura e identidade surdas: encruzilhada de lutas sociais e teóricas. Educação e sociedade, 26(91), 565-582.

Santos, K.R.O.R.P. (2011). Formação continuada e necessidades formativas de professores na educação de surdos da rede pública da cidade do Rio de Janeiro. Tese de Doutorado, Universidade Metodista de Piracicaba, Programa de Pós Graduação em Educação, São Paulo, Brasil.

Silva, C.M.S. (2014). Processos de escolarização do Distrito Federal: o que dizem os profissionais da escola sobre a inclusão de surdos?Dissertação de Mestrado, Universidade de Brasília, Brasília, DF.

Silva, C.M., Silva, D.N.H., \& Silva, R.C. (2013). Inclusão e Processos de Escolarização: Narrativas de Surdos sobre Estratégias Pedagógicas Docentes. Em Associação Brasileira de Psicologia do Desenvolvimento (org.). IX Congresso Brasileiro de Psicologia do Desenvolvimento. João Pessoa: Universidade Federal da Paraíba.

Silva, C.M., Silva, D.N.H., \& Silva, R.C. (2014). Inclusão e processos de escolarização: narrativas de surdos sobre estratégias pedagógicas docentes. Psicologia em Estudo, 19(2), 261-271.

Skliar, C. (1998). Os estudos em Educação: problematizando a normalidade. Em C. Skliar (Org.), A surdez: um olhar sobre as diferenças. Porto Alegre: Mediação.
Skliar, C. (2003) Perspectivas políticas e pedagógicas da educação bilíngüe para surdos. Campinas: Mercado das Letras.

Skliar, C.. (Org.). (2006). Educação \& exclusão: abordagens sócioantropológicas em educação especial ( $5^{\mathrm{a}}$ ed.). Porto Alegre: Mediação. (Trabalho original publicado em 1997).

Slomski, V. G. (2010). Educação Bilíngue para surdos: concepções e implicações práticas (1a. ed.) Curitiba: Editora Juruá.

Soares, R.S. (2013). Educação Bilíngue de surdos: desafio para formação de professores. Dissertação de Mestrado. Universidade de São Paulo, São Paulo, SP.

Souza, R. M. \& Lippe, E. M.O. (2012). Decreto 6.949/2009: avanço ou retorno em relação à Educação dos Surdos? Caleidoscópio, 10(1), 12-23.

Witkoski, S.A. (2009). Surdez e preconceito: a norma da fala e o mito da leitura da palavra falada. Revista Brasileira de Educação, 14(42), 565-575.

Witkoski, S. A. \& Baibich-Faria, T. M. (2010). A importância da Língua de Sinais para as pessoas surdas na construção de uma linguagem plena e genuína. Revista Contrapontos, 10(3), 338-344.

\section{Sobre as autoras}

Carine Mendes da Silva (carine_gnt@hotmail.com)

Pedagoga pela Universidade de Brasília e Mestre em Psicologia/Processos de Desenvolvimento Humano e Saúde.

Daniele Nunes Henrique Silva (daninunes74@gmail.com)

Professora no Programa de Pós-graduação em Processos de Desenvolvimento Humano e Saúde/ Instituto de Psicologia da Universidade de Brasília.

Trabalho derivado da dissertação de Mestrado de Carine Mendes da Silva, apresentada ao Programa de Pós-graduação em Processos de Desenvolvimento Humano e Saúde do Instituto de Psicologia da Universidade de Brasília. A pesquisa foi financiada pelo Reuni/Capes e submetida ao Comitê de Ética de Ciências Humanas da Universidade de Brasília. 
